\title{
Regional Approach to Making Nitrogen Fertilizer Rate Decisions for Corn ${ }^{1}$
}

\author{
John E. Sawyer and Emerson D. Nafziger ${ }^{2}$ \\ Iowa State University, Ames, IA and University of Illinois, Urbana, IL
}

\section{Introduction}

Nitrogen fertilizer is one of the largest input costs for growing corn. Across the Corn Belt, $\mathrm{N}$ is typically the most yield-limiting nutrient. Facing record high $\mathrm{N}$ fertilizer prices and potential supply problems, producers are concerned about $\mathrm{N}$ fertilization rates. Soil fertility researchers and extension specialists from seven states across the Corn Belt (see list in acknowledgements section) have been discussing corn $\mathrm{N}$ fertilization needs and evaluating $\mathrm{N}$ rate recommendation systems for approximately the past two years. These discussions could not have been timelier considering the current $\mathrm{N}$ fertilizer issues.

In recent years $\mathrm{N}$ recommendation systems have become more diverse across states in the Corn Belt. Of particular significance has been the movement away from yield goal as a basis of $\mathrm{N}$ rate decisions in some states to other methods such as cropping system (Iowa) or soil specific yield potential (Wisconsin). Research from across the Corn Belt has also been indicating that economic optimum $\mathrm{N}$ rate (EONR) does not vary according to yield level. At the same time, corn yields have been at historic high levels, leading to increases in yield goal. This has added to concerns that increasing yield-based $\mathrm{N}$ rates are often found to be substantially greater than EONR observed in $\mathrm{N}$ rate trials. Also, watersheds being targeted to receive incentive and costshare funds for $\mathrm{N}$ rate management sometimes cross state boundaries, which causes problems if suggested rates are not consistent. These issues have increased uncertainty regarding current $\mathrm{N}$ rate recommendations.

An outcome of the multi-state discussions has been development of a consistent approach for $\mathrm{N}$ rate guideline development that can be utilized on a regional basis. This does not necessarily mean that fertilizer $\mathrm{N}$ rates will be the same across states. Rather, there is a common approach to guideline development. Depending upon the research database, rates could be the same or quite different. Another outcome of this approach has been an improved ability to evaluate the economic returns to $\mathrm{N}$, and the ability to estimate the most profitable fertilizer $\mathrm{N}$ rates. This has become very valuable information for dealing with today's high $\mathrm{N}$ fertilizer prices and water quality issues.

\section{Maximum Return to N Approach (MRTN)}

The method utilized for developing the regional approach to $\mathrm{N}$ rate guidelines for corn was outlined by Nafziger et al. (2004) in a paper presented at the 2004 North Central ExtensionIndustry Soil Fertility Conference. The underlying principle is to have rate guidelines based directly from results of many $\mathrm{N}$ response trials. Databases of recent response trials represent a population of potential responses to $\mathrm{N}$. Subsets are assembled for specific rotations or other

\footnotetext{
${ }^{1}$ This paper will be presented at various conferences and workshops, including but not limited to the North Central Extension-Industry Soil Fertility Conference, November 16-17, 2005, Des Moines, IA.

${ }^{2}$ Associate Professor of Agronomy, Iowa State University and Professor of Crop Sciences, University of Illinois.
} 
factors that may influence $\mathrm{N}$ response. Analysis of economic net return to $\mathrm{N}$ across all sites in the datasets provides the basis for $\mathrm{N}$ rate guidelines. Net return is calculated from corn yield increase to $\mathrm{N}$ minus fertilizer $\mathrm{N}$ cost. The point of maximum return to $\underline{\mathrm{N}}$ (MRTN) is the most profitable $\mathrm{N}$ rate. Since net return is relatively constant around the MRTN rate, net return within $\$ 1.00$ /acre of the MRTN defines an $\mathrm{N}$ rate range that provides similar profitability.

An example result from MRTN calculation is shown in Fig. 1 for a large corn following soybean (SC) $\mathrm{N}$ response trial dataset from Iowa. Net return is influenced by $\mathrm{N}$ and corn prices, and the MRTN and profitable $\mathrm{N}$ rate range can be easily calculated for different prices. Net return will vary depending upon specific $\mathrm{N}$ and corn prices, but the MRTN rate remains constant when the ratio of these prices ( $\$ / \mathrm{lb}: \$ / \mathrm{bu})$ is the same. Details of the MRTN approach can be found in Nafziger et al. (2004) and a recently developed regional publication (see additional information section below). Following is an outline of the steps in the calculation of MRTN.

* Yield data are collected from replicated, multi-rate $\mathrm{N}$ response trials.

* A computer program is used to fit a line to the yield for the $\mathrm{N}$ rates at each site to provide a mathematical equation of that line.

* Datasets of site response curves are accumulated for specific situations, such as corn in different rotations.

* For each site in a dataset, values are calculated from the response curve equation at 1-lb $\mathrm{N}$ rate increments from zero to $240 \mathrm{lb}$ N/acre. From this information yield increase (above the yield at zero $\mathrm{N}$ ), gross dollar return from that yield increase, fertilizer cost, and net return are calculated. Economic values are calculated based on specified $\mathrm{N}$ fertilizer and corn grain prices.

* Net return is averaged across all sites in the dataset for each specific rotation.

* The $\mathrm{N}$ rate with the largest net return is the MRTN rate. Nitrogen rates with net return within \$1.00/acre of the MRTN provide a range of $\mathrm{N}$ rates with similar profitability.

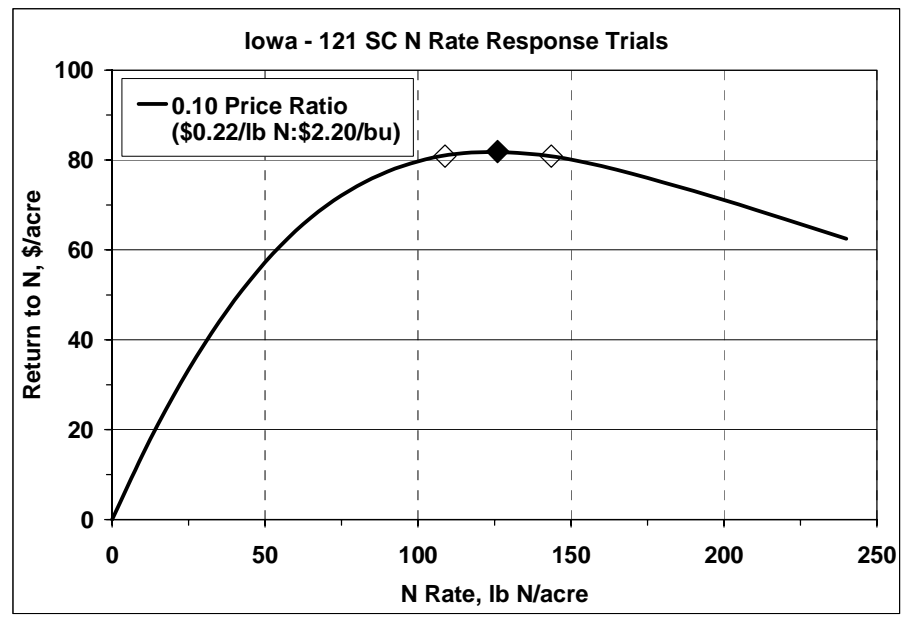

Figure 1. Return to $\mathrm{N}$ from 121 Iowa corn following soybean site-years. The MRTN rate is indicated by the closed symbol and the $\mathrm{N}$ rates (HIGH and LOW) defining the ends of a range of similar profitability (within $\$ 1.00$ /acre of the MRTN) are indicated by the open symbols. 


\section{Regional Database Analysis}

Nitrogen response data were assembled from 698 replicated N rate trials conducted from 19832004 in Illinois, Iowa, Michigan, Minnesota, Ohio, and Wisconsin (Fig. 2). All sites in the database were non-irrigated and had either spring preplant or sidedress fertilizer $\mathrm{N}$ application. Data were accumulated for corn following corn (CC) and SC. The number of sites by state and rotation was: Illinois - 93 CC, 185 SC; Iowa - 60 CC, 136 SC; Minnesota - 73 CC, 55 SC; and Wisconsin - 39 CC, 34 SC. Grain yield N response curves were determined for all sites and then accumulated into a database. Subsets of the database were sorted by state and rotation. These subsets were analyzed separately using the MRTN approach. The number of sites from Michigan and Ohio was limited; therefore results are not presented separately for those states. Characteristics of sites in the database: approximately $65 \%$ of sites were loess parent material soils and $31 \%$ had glacial till parent material; $12 \%$ were no-tilled and $88 \%$ had tillage; $7 \%$ had a manure history; $85 \%$ were soils classified as very high yield potential and $12 \%$ high yield potential.

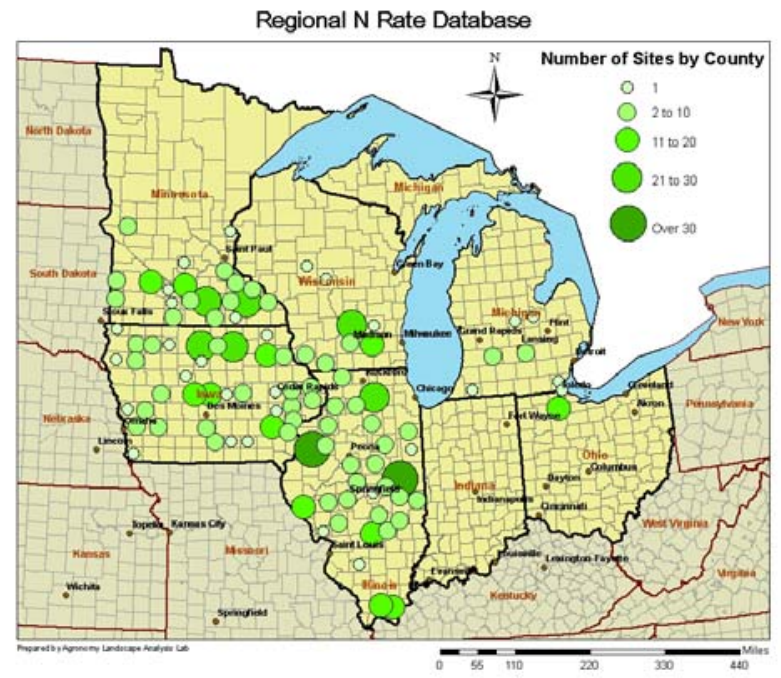

Figure 2. Geographic location and density of N response trial sites.

Across the multi-state database, the MRTN rate (0.10 price ratio, $\$ 0.22 / \mathrm{lb} \mathrm{N}: \$ 2.20 / \mathrm{bu}$ ) for SC is $140 \mathrm{lb} \mathrm{N} /$ acre (389 sites) and for CC is $161 \mathrm{lb}$ N/acre (244 sites). This calculation does not include non-responsive sites for each rotation (that is, sites with no yield increase from applied $\mathrm{N}$ ). If the non-responsive sites are included (38 for SC and 27 for CC), the MRTN rates decrease by only $4 \mathrm{lb} \mathrm{N} / \mathrm{acre}$. While these "entire-region database" $\mathrm{N}$ rates may seem reasonable, they are likely not most appropriate for individual states. Climate, soils, and production practices are different across the Corn Belt, so it is reasonable that needed $\mathrm{N}$ fertilization rates would vary. Separate analyses of the datasets from each state shows that MRTN rates are indeed different across the four states (Fig. 3). Some states have quite similar MRTN rates (Minnesota and Wisconsin being good examples), others are different. It appears that the more northern region (Minnesota and Wisconsin) has lower $\mathrm{N}$ fertilization requirement, which could easily be due to higher organic matter soils and climatic differences. Guidelines developed from the MRTN analysis would therefore be different between some states. Consistency comes from the similar analysis process, not from having the same $\mathrm{N}$ rate guidelines across the whole region. 

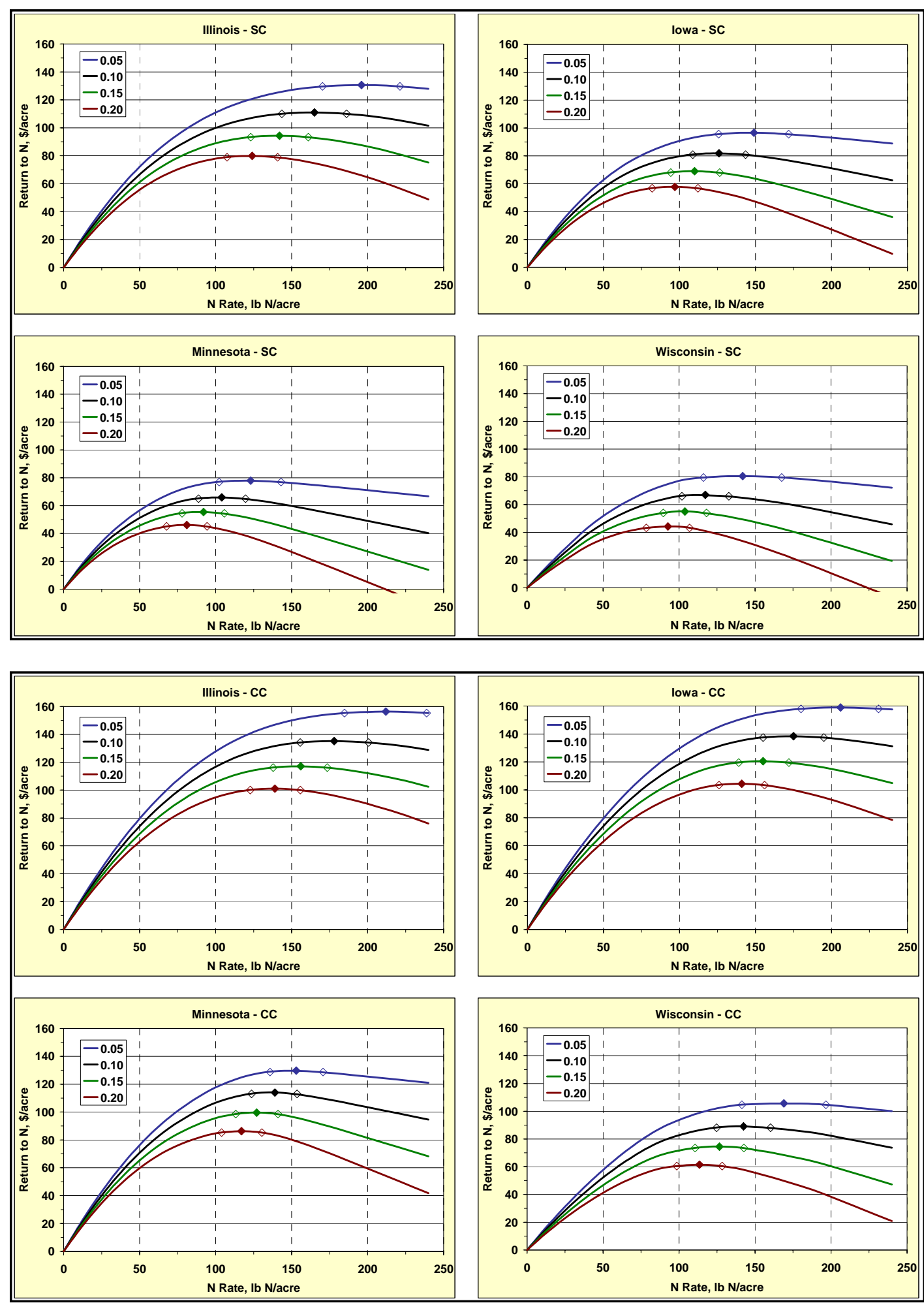

Figure 3. Net return to N, MRTN, and profitable $\mathrm{N}$ rate ranges for SC and CC datasets from the four states. Corn grain price was held constant at $\$ 2.20 / \mathrm{bu}$ and $\mathrm{N}$ prices at $\$ 0.11, \$ 0.22$, $\$ 0.33$, and $\$ 0.44 / \mathrm{lb} \mathrm{N}$ give price ratios of $0.05,0.10,0.15$, and 0.20 , respectively. 
The prices of $\mathrm{N}$ and corn affect the net return to $\mathrm{N}$, as well as the point of MRTN and width of the profitable $\mathrm{N}$ rate range around the MRTN (Fig. 3). As $\mathrm{N}$ becomes more expensive relative to corn price (that is, as the price ratio $\$ / \mathrm{lb}: \$ /$ bu increases), net return is reduced, MRTN is reduced, the width of the profitable $\mathrm{N}$ rate range decreases, and economic penalty with high $\mathrm{N}$ rates (above optimum) becomes more severe.

Across the four states, the MRTN rate is higher for CC than SC. This follows the expected trend, and what has been measured in research studies for many years. The difference in MRTN rate is not consistent between states. For SC, at a 0.10 price ratio $(\$ 0.22 / \mathrm{lb} \mathrm{N}: \$ 2.20 / \mathrm{bu}$ corn), the MRTN rate is 163, 123, 101, and $107 \mathrm{lb}$ N/acre respectively for Illinois, Iowa, Minnesota, and Wisconsin datasets. For CC, the MRTN rate is 176, 174, 136, and $139 \mathrm{lb}$ N/acre respectively for Illinois, Iowa, Minnesota, and Wisconsin datasets. The largest difference between rotations is for Iowa data, the smallest for Illinois data, with Minnesota and Wisconsin intermediate. The MRTN rate difference between the Iowa SC and CC datasets (51 lb N/acre) is consistent with what has been suggested for the SC rotation effect for many years in Iowa (Voss and Shrader, 1979). In Illinois, this difference averages about $40 \mathrm{lb}$ N/acre when the two rotations are evaluated next to one another in the same field. Some of the reason the difference is less than the "soybean $\mathrm{N}$ credit" of $40 \mathrm{lb}$ in Illinois is because the Illinois SC and CC datasets have results from different sites. It is possible that some corn following corn is on more-productive soil. If so, then more of the $\mathrm{N}$ requirements may be provided by the soil. Although data were not accumulated for rotations other than SC and CC, the same MRTN approach can be applied when corn follows other crops. First- and second-year corn after forage legumes are good examples. All that is required is an adequate $\mathrm{N}$ response trial dataset.

While the analysis presented used each entire state database, subsets can be created to determine if site conditions, management history, or regions within or across states should have the same or different rate guidelines. Here are a few examples. For the Illinois SC dataset, the MRTN is slightly lower for SC in the northern portion of Illinois (163 lb N/acre) versus southern Illinois (179 lb N/acre). Although the difference is not large, rate guidelines could be adjusted for these two regions. As mentioned earlier, this difference in $\mathrm{N}$ fertilization need could be due to different soils and climatic conditions. For the Iowa SC dataset, the MRTN rate is similar when grouped into various yield ranges (128 lb N/acre for 0-150 bu/acre; $126 \mathrm{lb}$ N/acre for 150-200 bu/acre; and $127 \mathrm{lb} \mathrm{N} /$ acre for 200+ bu/acre). This indicates that different $\mathrm{N}$ rate guidelines are not needed based on yield level in Iowa. For the entire multi-state database, the MRTN rate is $4 \mathrm{lb}$ $\mathrm{N} /$ acre higher for no-till versus tilled soils; not a large enough difference to suggest $\mathrm{N}$ rate adjustment based on tillage. Other subsets can be analyzed in the same manner. Most such analyses conducted to date suggest that grouping data by site characteristics does little to improve $\mathrm{N}$ rate guidelines.

\section{What This Means for Corn N Rate Guidelines}

An example of how $\mathrm{N}$ rate guidelines based on the MRTN approach might look is given in Table 1 for the Iowa SC and CC datasets. Choice of a $\mathrm{N}$ rate can be adjusted by using current prices (price ratio); moving between MRTN rates as price ratios change; moving toward the low or high end of the profitable range based on price ratios, availability of enterprise capital, soil 
productivity potential, yield-limiting factors, external perception, or production risk tolerance/aversion. This guideline approach gives producers, and their advisers, opportunity to adjust choice of $\mathrm{N}$ rate.

The impact of using the regional approach for making corn $\mathrm{N}$ rate decisions will likely be different across states. How much the guidelines will change from those currently used in an individual state will depend on the recommendation system currently in use as well as the results of the MRTN analysis using that state's $\mathrm{N}$ response data. More important will be the overall benefits from having a common approach used in each state. As new data are generated, they can be added to the database to improve the basis for the calculations. Not only will the analysis of recent response data provide up-to-date information, but the economic focus will help producers choose $\mathrm{N}$ application rates that have potential for maximizing return. With the current issues of high price and uncertain supply, having current information will provide needed help with tough $\mathrm{N}$ fertilization decisions.

Table 1. Example $\mathrm{N}$ rate fertilization guidelines for SC and CC in Iowa based on N:corn price ratios and economic return calculated by the MRTN approach.

\begin{tabular}{|c|c|c|c|c|c|c|}
\hline \multirow[b]{2}{*}{ Price Ratio } & \multicolumn{3}{|c|}{ SC } & \multicolumn{3}{|c|}{$\mathrm{CC}$} \\
\hline & $\mathrm{LOW}^{\dagger}$ & MRTN & $\mathrm{HIGH}^{\dagger}$ & $\mathrm{LOW}^{\dagger}$ & MRTN & $\mathrm{HIGH}^{\dagger}$ \\
\hline \$/lb:\$/bu & --- & --- & $---l b$ & cre - - - . & ---- & --- \\
\hline 0.05 & 125 & 145 & 170 & 180 & 200 & 230 \\
\hline 0.10 & 105 & 125 & 145 & 155 & 175 & 195 \\
\hline 0.15 & 90 & 110 & 125 & 140 & 155 & 170 \\
\hline 0.20 & 80 & 95 & 110 & 125 & 140 & 155 \\
\hline
\end{tabular}

${ }^{\dagger}$ LOW and HIGH rates approximate the profitable range for \$1.00/acre below and above the MRTN for each price ratio.

The actual impact of applying the MRTN approach will likely be smaller in Iowa and Wisconsin than in some other states. The currently suggested $\mathrm{N}$ rates in those two states appear close to that derived from the MRTN analysis. Also, both states had previously moved away from yield-based recommendations. Wisconsin recommendations had already become more directly based on results of $\mathrm{N}$ rate trials. In Iowa, current MRTN analysis is providing $\mathrm{N}$ rates that are strikingly similar to fertilizer $\mathrm{N}$ rate ranges suggested for many years. In other states, especially those utilizing yield-based rate systems, the potential impact will be large. Even if rates don't change much, introducing a new system will be a significant conceptual challenge. For producers that use a yield-based approach, and have been producing exceptionally high corn yields, the rate guidelines developed from the MRTN approach will likely be lower than those used now. This will be a concern to producers, but it is a change that research indicates should happen. That is, $\mathrm{N}$ rates driven by yield-based recommendations are substantially higher than the EONR found $\mathrm{N}$ response trials, especially for corn following soybean. 
Some uncertainty always exists in regard to having sufficient $\mathrm{N}$ to meet crop needs. This occurs because of variation in optimum $\mathrm{N}$ among sites and among years at a site. Producer concerns usually focus on the potential for severe yield and economic loss if $\mathrm{N}$ is deficient, as shown with low rates in Fig. 3. With inexpensive $\mathrm{N}$, this can easily lead to high $\mathrm{N}$ application rates as a way to alleviate such uncertainty. The MRTN results shown in Fig. 3 indicate that when $\mathrm{N}$ is inexpensive compared to corn price, rates well above the MRTN result in only minor decline in net return. However, as $\mathrm{N}$ becomes more expensive relative to corn price, high application rates will result in significant economic losses. Therefore, using high $\mathrm{N}$ rates to "ensure" high yield should be reconsidered with today's $\mathrm{N}$ prices. The flat net return surrounding the $\mathrm{N}$ rate at MRTN reflects the small yield change that occurs near optimum $\mathrm{N}$. This indicates that choosing an "exact" $\mathrm{N}$ rate is not critical for optimal yield, and this should give producers confidence that $\mathrm{N}$ applications based on MRTN will be adequate.

To help understand uncertainty with choice of a particular $\mathrm{N}$ rate, percent chance of $\mathrm{N}$ sufficiency (outlined in Nafziger et al., 2004) can be calculated for each rate guideline and price ratio (example for the Iowa datasets given in Fig. 4). The chance of a chosen $\mathrm{N}$ rate being a sufficient rate (conversely, a "not deficient" rate) can be determined. While it may seem desirable to have $\mathrm{N}$ rate sufficiency near $100 \%$, that is, have little to no $\mathrm{N}$ deficiency risk, it is not economical to apply $\mathrm{N}$ at rates providing that level of sufficiency. This can be seen by comparing the $\mathrm{N}$ rates at high level of sufficiency in Fig. 4 for the Iowa datasets with the net return at the same $\mathrm{N}$ rates in Fig. 3 for the same datasets. In general, $\mathrm{N}$ rates at the MRTN tend to be at or above the EONR in some 60 to 80 percent of the trials in a database. While 20 to 40 percent chance of "insufficiency" may seem high, the nature of the response curves is such that the economic penalties for over-application and under-application tend to be at a minimum at the MRTN. Therefore, while producers bear some level of risk in order to maximize economic return from $\mathrm{N}$ fertilization, the MRTN provides the best estimate, based on actual data, of the $\mathrm{N}$ rate at which such risk is minimized.
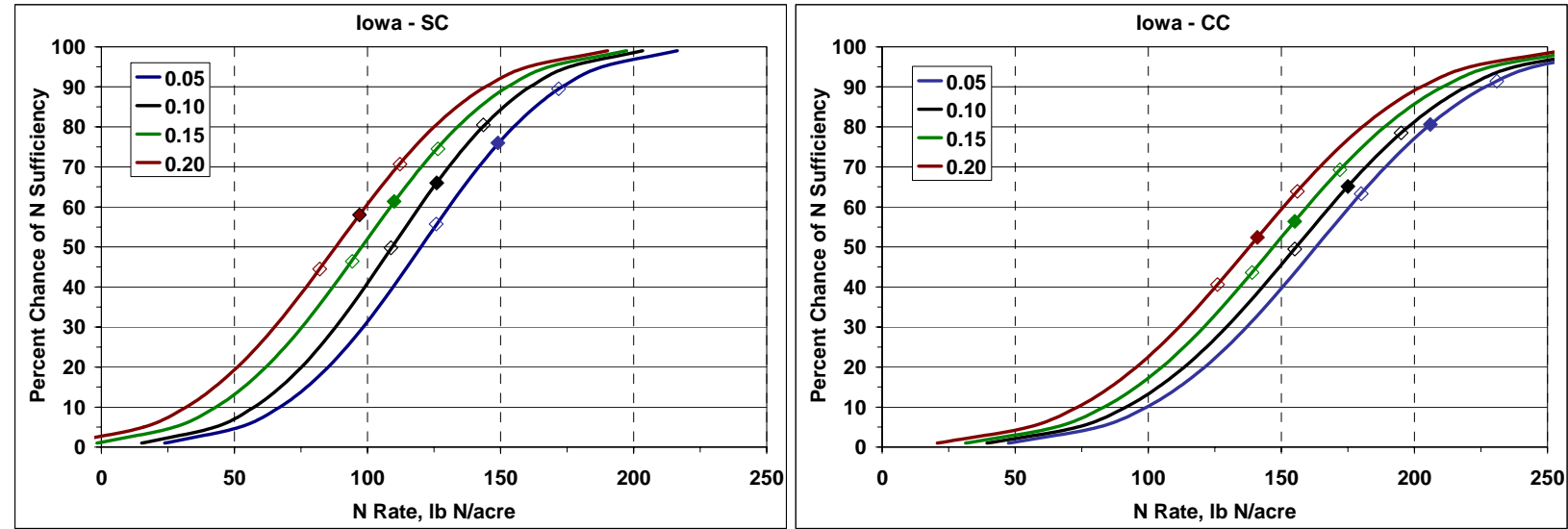

Figure 4. Chance of $\mathrm{N}$ rate sufficiency from the Iowa SC and CC datasets. The MRTN rate is indicated by the closed symbols and the $\mathrm{N}$ rates (HIGH and LOW) defining the range of similar profitability (within $\$ 1.00 /$ acre of the MRTN) indicated by the open symbols. 


\section{Summary Comments Regarding the MRTN Approach}

Nitrogen rate guidelines should provide producers the opportunity to maximize economic return from applied $\mathrm{N}$. Yield responses measured in $\mathrm{N}$ rate trials conducted across many sites provides the database needed for economic analysis. The MRTN approach provides a flexible method to develop $\mathrm{N}$ rate guidelines directly from response databases, either on a local or regional basis. Of most importance, the MRTN approach incorporates economic analysis, is based on maximizing return to $\mathrm{N}$ fertilization, and uses up-to-date $\mathrm{N}$ research data. With the ease of calculation, guidelines can be adjusted for various factors affecting corn $\mathrm{N}$ fertilization need such as rotation, geographic location, etc. and economic factors like $\mathrm{N}$ fertilizer and corn prices. Additional features such as environmental penalties for over-application or grain quality effects of $\mathrm{N}$ nutrition can be incorporated into the calculations as well. For example, excess $\mathrm{N}$ could be assigned a cost per $\mathrm{lb}$ of $\mathrm{N}$, or a decrease in protein content as a consequence of underapplication could be assigned as a penalty to the corn price.

Because the MRTN approach relies on current $\mathrm{N}$ rate response data, there must be an adequate number of trials available in order to develop or update guidelines. This requires an aggressive and on-going research program, especially if $\mathrm{N}$ guidelines are desired for specific geographic locations, soils, rotations, or other situations. The more data that are available and the more robust the $\mathrm{N}$ response database, the better $\mathrm{N}$ rate guidelines will be and the more specific they can become.

\section{Summary Observations from Application of the MRTN Approach}

* The MRTN approach, through direct analysis of $\mathrm{N}$ response trial datasets, provides a straightforward development of $\mathrm{N}$ rate guidelines.

* The MRTN approach is useful not only for providing $\mathrm{N}$ rate guidance, but also for increasing understanding of corn response to $\mathrm{N}$ application and economic profitability.

* The MRTN rate and profitable range of $\mathrm{N}$ rates surrounding the MRTN provides guidelines for rate selection and flexibility for producers in addressing risk and price fluctuation.

* Higher $\mathrm{N}$ prices relative to corn grain prices (larger price ratio, $\$ / \mathrm{lb}: \$ / \mathrm{bu}$ ) results in reduced net return, lower MRTN rate, reduced width of the profitable $\mathrm{N}$ rate range around the MRTN, and greater economic penalty with $\mathrm{N}$ rates above optimum.

* Nitrogen rates well below optimum result in severe reduction in net return, especially with more N-responsive crop sequences such as CC.

* If adequate data exist, subsets can be created to determine if production practices, management history, prior crop, or regions within or across states could have similar or different rate guidelines.

\section{Additional Information}

A regional publication called “Concepts and Rationale for Regional N Rate Guidelines for Corn” will be available in the near future. Check with the Extension program in your state for availability of printed copies or on-line web access. The publication covers the regional guideline 
approach outlined here and provides detailed results from applying the MRTN approach to the four-state $\mathrm{N}$ response databases.

Also, a web tool was developed, the "Corn Nitrogen Rate Calculator," that is based on the MRTN approach. It calculates the MRTN, profitable $\mathrm{N}$ rate range, net return, chance of $\mathrm{N}$ sufficiency, and other information directly from the $\mathrm{N}$ response trial databases for Illinois, Iowa, Minnesota, and Wisconsin. Calculations can be computed for CC or SC, and can be compared with up to four sets of $\mathrm{N}$ fertilizer and corn prices. This calculator is located at http://extension.agron.iastate.edu/soilfertility/nrate.aspx.

\section{Acknowledgements}

Other individuals involved in development of the regional approach to $\mathrm{N}$ rate guidelines and compiling state corn N response trial databases include: Sylvie Brouder, Purdue University; Larry Bundy, University of Wisconsin; Brad Joern, Purdue University; Robert Hoeft, University of Illinois; Randy Killorn, Iowa State University; Carrie Laboski, University of Wisconsin; Robert Mullen, The Ohio State University; Gyles Randall, University of Minnesota; and George Rehm, University of Minnesota. Without the input and guidance provided by this group development of the regional approach would not have been possible.

Thanks are extended to the many individuals and researchers who have worked tirelessly to conduct the $\mathrm{N}$ response trials and to the producers who donated land and time for these trials.

\section{References}

Nafziger, E.D., J.E. Sawyer, and R.G. Hoeft. 2004. Formulating N recommendations for corn in the corn belt using recent data. In Proc. N. C. Ext.-Ind. Soil Fertility Conf., Des Moines, IA. 17-18 Nov., 2004. Potash and Phosphate Inst., Brookings SD.

Voss, R.D., and W.D. Shrader. 1979. Crop rotations-effect on yields and response to nitrogen. Publication pm-905 (out of print). Iowa State University Extension, Ames, IA. 